\title{
Application of the response surface method to optimize alkali activated cements based on low-reactivity ladle furnace slag
}

\author{
Claver Pinheiro ${ }^{a}$, Sara Rios ${ }^{a}, *$, António Viana da Fonseca ${ }^{a}$, Ana Fernández-Jiménez ${ }^{b}$, Nuno Cristelo ${ }^{c}$ \\ ${ }^{a}$ CONSTRUCT-GEO, Faculty of Engineering, University of Porto, Rua Dr. Roberto Frias, s/n 4200-465, Porto, Portugal \\ b Instituto Eduardo Torroja (IETCC), CSIC, C/Serrano Galvache 4, 28033 Madrid, Spain

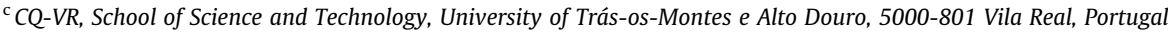

\section{H I G H L I G H T S}

- Use of a steel slag with no applicability outside the steel industry facilities.

- This low reactivity steel slag was successfully applied for alkaline activation.

- A rational methology based on a response surface method was used for the optimisation process.

- Regression equations for the compressive and flexural strength at 7 and 28 days.

- The UCS achieved $32.27 \mathrm{MPa}$ and $44.25 \mathrm{MPa}$ at 7 and 28 days without curing at high temperatures.

\section{A R T I C L E I N F O}

\section{Article history:}

Received 3 April 2020

Received in revised form 25 June 2020

Accepted 13 July 2020

Available online 25 July 2020

\section{Keywords:}

Alkaline-activation

Response surface design

Fly ash

Steel slag

Microstructural analysis

Unconfined compression strength

Flexural strength

\begin{abstract}
A B S T R A C T
Steel-making slags, resulting from basic oxygen furnaces or electric arc furnaces are heavily applied in the construction industry, as an aggregate for pavements or concrete. Although possessing a significant crystalline content, it is expected that, if properly milled, the reactivity of these slags can increase up to a point when they are viable to produce alkaline cements. The aim of this study was the application of a response surface method to design the experimental work required to optimise the composition of an alkaline cement based on ladle furnace slag, a specific type of steel slag (SG). Fly ash (FA) was also added, in a precursor role, and the activation was achieved with an alkaline solution prepared with sodium silicate (SS) and sodium hydroxide (SH). The factors/variables considered were the activator index $\mathrm{X}=\mathrm{SS} /$ $(\mathrm{SS}+\mathrm{SH})$, the precursor index $\mathrm{Y}=\mathrm{SG} /(\mathrm{SG}+\mathrm{FA})$ and the $\mathrm{SH}$ concentration $(\mathrm{Z})$. The output variables were the unconfined compression strength and the flexural strength, after 7 and 28 days curing. Results indicate that the activator index $(\mathrm{X})$ was the most influential variable, followed by the precursor index $(\mathrm{Y})$. Microstructural analysis of selected pastes was also performed, using scanning electron microscopy and energy dispersive spectroscopy. The ideal composition obtained for the alkaline cement was the mixture constituted by $\mathrm{X}=0.75, \mathrm{Y}=0.5$ and $\mathrm{Z}=10$ (activator: $75 \% \mathrm{SS}$ and $25 \% \mathrm{SH}$; precursor: $50 \% \mathrm{SG}$ and $50 \%$ $\mathrm{FA}$; SH concentration $=10$ molal). This mixture achieved $8.70 \mathrm{MPa}$ of flexural strength and $44.25 \mathrm{MPa}$ of compressive strength which is reasonable for the required application (soil stabilisation).
\end{abstract}

(c) 2020 Elsevier Ltd. All rights reserved.

\section{Introduction}

Climate change in recent decades has been assigned by several experts to the excessive emissions of greenhouse gases and toxic pollutants. The consequences of climate change have been visible in the intensification of natural catastrophes resulting in the loss of thousands of lives as well as vast economic losses. The need to

\footnotetext{
* Corresponding author.

E-mail addresses: clavergiovanni@gmail.com (C. Pinheiro), sara.rios@fe.up.pt (S. Rios), viana@fe.up.pt (A. Viana da Fonseca), anafj@ietcc.es (A. Fernández-Jiménez), ncristel@utad.pt (N. Cristelo).
}

reduce green-house gases is an increasingly entrenched principle in society, encouraging the production and use of new materials to reduce the effects of Portland cement production which releases a significant amount of carbon dioxide to the atmosphere.

In fact, the cement industries are among those penalized by the Kyoto Protocol, signed in 1997 and more recently in the Paris Agreement, 2016, due to excessive emissions. However, the massive production of Portland cement has also caused other environmental impacts due to the use of clay and limestone that are becoming increasingly scarce. To produce a ton of Portland cement, several tons of raw materials are extracted from the earth, the 
extraction being faster than the sustainability of the system. On the other hand, as the world's population grows, the need for new constructions and infrastructures increased the consumption of raw materials and the production of waste. Rattanasak \& Chindaprasirt [1] have already noted that the sharp growth of concrete production has led to an increase of cement production to quantities never reached.

One potential method of addressing both problems (the increasing demand for housing materials and the increasing volume of industrial waste) is to use these wastes as construction materials [2]. Today, the reuse of waste from different industrial processes as new materials for civil construction has been increasingly developed to promote circular economy. Alkaline activated cements can significantly reduce carbon dioxide emissions as well as the consumption of non-renewable natural resources in civil engineering applications, relatively to ordinary Portland cement (OPC), since waste materials can be used instead of natural aggregates [3].

Alkaline activation (AA), can be described as a reaction between aluminosilicate materials (precursors) and alkali or alkali-based earth substances namely, $\mathrm{ROH}, \mathrm{Ca}(\mathrm{OH})_{2}, \mathrm{R}_{2} \mathrm{CO}_{3}, \mathrm{R}_{2} \mathrm{~S}, \mathrm{Na}_{2} \mathrm{SO}_{4}$, $\mathrm{CaSO}_{4} \cdot 2 \mathrm{H}_{2} \mathrm{O}, \mathrm{R} 2(\mathrm{n}) \mathrm{SiO}_{2}$, in which $\mathrm{R}$ represents an alkaline ion, such as sodium ( $\mathrm{Na}$ ) or potassium $(\mathrm{K})$, or an alkaline-earth ion, such as calcium (Ca). This technique is particularly adequate to create binders based on residues, such as fly ash or slag, which constitute very effective options due to their amorphous or vitreous aluminosilicate microstructure [4-5]. The reactions begin with destruction of the covalent bonds $\mathrm{Si}-\mathrm{O}-\mathrm{Si}, \mathrm{Al}-\mathrm{O}-\mathrm{Al}$, and $\mathrm{Al}-\mathrm{O}-\mathrm{Si}$ present in the glassy phase of the precursor. The products precipitate and reorganize into more stable and ordered structures of Si-O-Al and $\mathrm{Si}-\mathrm{O}-\mathrm{Si}$ [6]. When calcium is present in the mixture in significant amounts, the formation of a gel type C-A-S-H with 2D structure is favoured. However, in a material with low calcium content, the gel formed is an amorphous aluminosilicate gel (sometimes designated as N-A-S-H gel) with 3D structure [7]. In some circumstances (for intermediate calcium contents and high $\mathrm{pH}$ values) both types of cementitious gels are present and interacting leading to structural and compositional changes in the process [8-9].

In the present work, a mixture of low calcium fly ash (FA), which is commonly used in this type of experiments [10-12], and steel slag (SG) were used to produce an alkali activated cement (AAC). The application behind the development of this AAC was soil improvement under the phreatic table. Therefore, it was important to include a high-calcium source, like the slag, to increase the rate of the reactions and the subsequent production of the binding gel [13], especially under the mild temperatures expected underground. Steel slags, namely ladle slags, are not very often used in alkaline activation due to their high crystalline content. This type of slags are less desirable as an aggregate since their usually slow cooling process produces a very significant content of fine powders [14], although previous studies reported significant strength increase when natural aggregates were replaced by combinations of ladle slag and blast furnace slag [15]. However, the use of this slag has economic and environmental benefits since there is not a known application outside the steel industry. For that reason, the aim of the present research was the optimization of the mechanical strength of this AAC resulting from the activation of these precursors, by an alkaline solution based on sodium hydroxide and sodium silicate. The mechanical behaviour was analysed by compression and flexural strength tests, while the microstructural analysis was made by the interpretation of scanning electron micrographs coupled with Energy Dispersive Spectroscopy and Xray diffraction.

The design of the experimental work was based on the response surface method (RSM), to obtain an appropriate mathematical model, capable of minimizing the required experiments while, at the same time, producing a highly effective tool for data analysis and interpretation, allowing efficiency and economy in the experimental process and scientific objectivity in the conclusions. Rios et al., [4] explains that these methods are especially advantageous for mixtures with several constituents, as is the case of AAC, where the best performing blend is the target. This is usually achieved by changing the amount of each constituent at a time, following the traditional method of changing a factor at a time. However, this methodology does not explain the interactions between variables, which can be obtained using complete factorial designs. If central and axial points are added to a two-level factorial design, the obtained composite design is considered suitable for surface response methods [16]. In this work, a face-centred composite design was used, which means that the axial points are at the centre of each face of the factorial space. Other authors have used response surface methods to optimise alkali activated binders [17] or concrete pastes [18] with different objectives (mixture optimization, identification of main variables, identification of outliers). In this particular work, predicting equations for compressive and flexural strength at 7 and 28 days were developed based on three input variables (activator index, precursor index and sodium hydroxide concentration).

\section{Materials and methods}

\subsection{Materials}

The ladle slag used in this study was collected at the Megasa Steel Industry of Maia, Portugal, where the corresponding electric arc furnace slag is already certified for use in construction, as an aggregate for pavement base layers or bituminous layers. It is a white powder, currently without any known application outside the steel industry. It presents a high calcium content, as showed in Table 1, although a significant portion is crystalline, which hinders its reactivity in terms of alkali activation reactions [19-20]. Furthermore, although some cementitious behaviour might be achieved, an increasing water content can severely reduce the strength development, due to the formation of metastable phases, as shown by Adesanya et al. [21]. The XRD reproduced in Fig. 1 shows some crystalline phases, mostly Calcium Silicate and Gehlenite. An amorphous phase was also detected, based on the halo between 28 and $35^{\circ}(2 \theta)$. The quantification of the vitreous content of the slag would have been desirable, but such experimental procedure is known to be very limited [14,20,22]. Nevertheless, several authors have used quantitative XRD (Rietveld) to estimate the vitreous phase in ladle slags, obtaining significantly different total values, like $60 \mathrm{wt} \%$ [23] - with the amorphous $\mathrm{CaO}$ representing between $45 \mathrm{wt} \%$ and $64 \mathrm{wt} \%$ of the total $\mathrm{CaO}$ in the slag; $21 \mathrm{wt} \%$ [24]; or $16 \mathrm{wt} \%$ [25].

The fly ash (FA) was collected at the PEGOP thermoelectric power plant, located in Pego, Portugal, where there is a significant production of this residue, often stored in a large area with high

Table 1

Composition of the solid materials.

\begin{tabular}{lll}
\hline Element & Slag (wt\%) & Fly Ash (wt\%) \\
\hline $\mathrm{CaO}$ & 54.9 & 4.68 \\
$\mathrm{SiO}$ & 23.5 & 54.84 \\
$\mathrm{MgO}$ & 8.5 & 1.79 \\
$\mathrm{Al}_{2} \mathrm{O}_{3}$ & 6.6 & 19.46 \\
$\mathrm{Fe}_{2} \mathrm{O}_{3}$ & 1.1 & 10.73 \\
$\mathrm{MnO}$ & 0.4 & - \\
$\mathrm{K}_{2} \mathrm{O}$ & - & 4.26 \\
$\mathrm{TiO}_{2}$ & - & 1.40 \\
$\mathrm{Na}_{2} \mathrm{O}$ & - & 1.65 \\
\hline
\end{tabular}




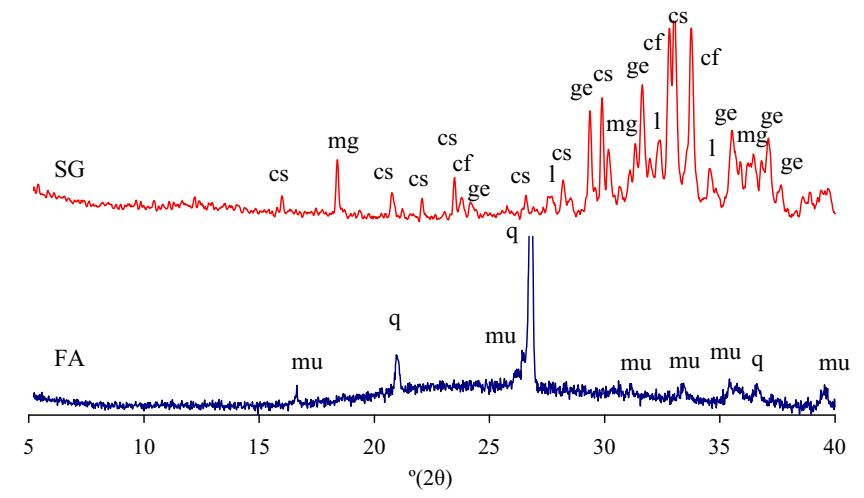

Fig. 1. X-ray diffraction pattern for the slag (SG) (cf - Calcium/Magnesium/Iron, cs Calcium Silicate, ge - Gehlenite, 1 - Larnite, mg - Magnetite) and fly ash (FA) (mu Mullite, q - Quartz).

significant management impacts. It is classified as type $\mathrm{F}$, according to ASTM standard C 618 [26] due to its low calcium content, as observed in Table 1. In terms of mineralogy (Fig. 1), this material showed some amorphous content, based on the halo between the 16 and $30^{\circ}(2 \theta)$, with quartz and mullite as the main crystalline phases. This is important since the lower the amorphisation degree, the lower the capacity for activation and, consequently, the lower the mechanical strength development [27]. Although the loss on ignition was not determined for this particular FA, a similar FA collected from the same installation, was only 2.59, as mentioned by Cristelo et al. [28].

Both the FA and the SG underwent a physical treatment, to increase their specific surface and, consequently, their reactivity. This was achieved by milling the original materials in a modified Los Angeles test machine, for two consecutive periods of $4 \mathrm{~h}$, after which at least $50 \%$ of the particles were smaller than $40 \mu \mathrm{m}$. Fig. 2 shows the particle size distribution of both powders, before and after milling for $8 \mathrm{~h}$.

The alkaline activator was a combination of sodium hydroxide and sodium silicate, both in solution form. Sodium hydroxide, originally in flake form, with a specific gravity of 2.13 at $20^{\circ} \mathrm{C}$ and $95-$ 99\% purity, was dissolved in water to the desired molal (m) concentration. The sodium silicate was already in solution form, with a specific gravity of 1.5 and $\mathrm{SiO}_{2} / \mathrm{Na}_{2} \mathrm{O}$ ratio of 2 by mass.

\subsection{Definition of the mixtures and testing procedures}

The evaluation of the RSM results explores the relations between the factors that affect the process, as well as those

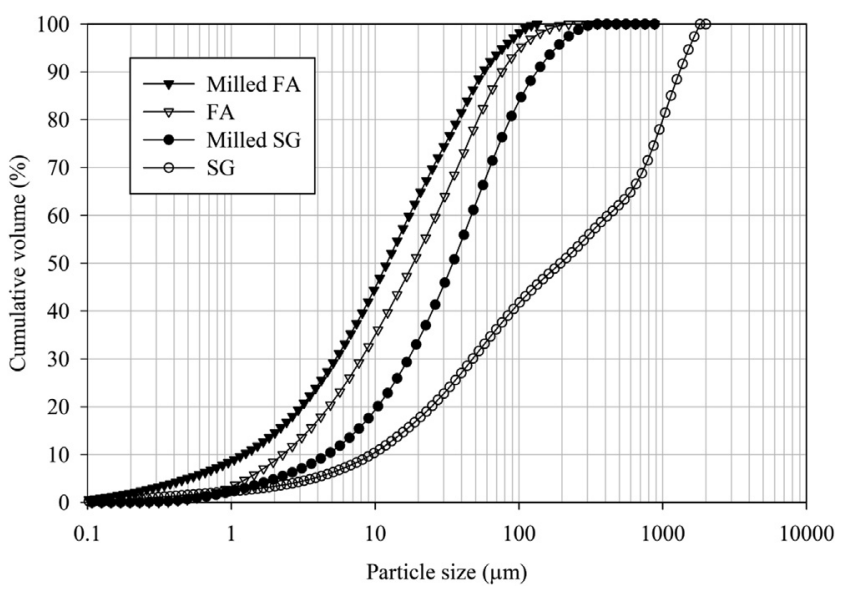

Fig. 2. Particle size distribution of fly ash (FA) and slag (SG), before and after milling. between the factors and the response, in order to minimize the experimental effort and maximize the relevant information collected from each experiment.

Possible variables in this study were the contents of each constituent of the AAC, namely the FA, SG, sodium silicate (SS), and sodium hydroxide $(\mathrm{SH})$. However, previous studies determined clear correlations between alternative variables and the mechanical properties of the AAC, namely the unconfined compression strength (UCS) [29-32]. Such variables usually include the liquid content of the mixture, the weight ratio between the two activator components, and the sodium hydroxide concentration. An additional parameter was included, which was the relation between FA and SG. The liquid content, in terms of the ratio between the quantity of activator solution and the quantity of slag and fly ash, was set constant to $\mathrm{L} / \mathrm{S}=0.4$, based on previous work from the authors $[4,33]$, using similar materials and conditions. It is important to notice that this method requires the input variables to be continuous so, the variables considered in the statistical study were the following:

- $\mathrm{X}=\mathrm{SS} /(\mathrm{SS}+\mathrm{SH})-$ activator index.

- $\mathrm{Y}=\mathrm{SG} /(\mathrm{SG}+\mathrm{FA})$ - precursor index.

- $\mathrm{Z}=\mathrm{SH}$ concentration - activator quality.

with variation ranges of $0.5-1.0$, for $\mathrm{X}$ and $\mathrm{Y}$, and $8-12$, for $\mathrm{Z}$. The value $\mathrm{X}=0.5$ corresponds to an activator composed of $50 \%$ SS $+50 \%$ SH, while $X=1$ reflects an activator with $100 \%$ SS. The value $Y=0.5$ corresponds to a mixture with $50 \% \mathrm{SG}+50 \% \mathrm{FA}$, while $\mathrm{Y}=1$ indicates that only SG is present. The $\mathrm{Z}$ values reflect the molality of the mixture, which was defined based on the literature [34-36]. This led to an experimental plan composed of a total of 16 mixtures, as defined by the model. All the mixtures are identified in Table 2, including the corresponding $\mathrm{X}, \mathrm{Y}$ and $\mathrm{Z}$ values and the liquid and solid contents, defined as a percentage of the total weight. It should be noted that, according to this methodology, the central point is repeated twice to assess the experimental error (mixtures 5 and 7 ).

The activator was prepared $24 \mathrm{~h}$ before the fabrication of the mixtures. The $\mathrm{SH}$ pellets were dissolved in water to the desired molal concentration and let to cool down at room temperature. The two solutions were then mixed, according to the desired activator index (variable X). After $24 \mathrm{~h}$, the solids (FA and SG) were dry mixed and added to the activator, followed by a 3-minute homogenization period, in an automatic mixer. The resulting paste was casted in $10 \times 10 \times 60 \mathrm{~mm}$ moulds. After two days, the specimens showed an adequate consistency, enough to be demoulded, after which they were stored in a temperature-controlled room $\left(20^{\circ} \mathrm{C}\right)$, to cure for 7 and 28 days, at $93 \%$ to $95 \%$ of relative humidity. To increase the reliability of the results, 3 replicates of each mixture were fabricated and tested (a procedure proposed by the RSM methodology), totalising 96 specimens (16 mixtures $\times 2$ curing times $\times 3$ replicates).

After the curing period, the specimens were tested for flexural strength, using the Köch-Steinegger procedure [37], consisting of a 3-point loading setup, with a support span of $50 \mathrm{~mm}$. This test was developed for the evaluation of the degradation of the material in a certain medium, through the loss of mechanical properties. The flexural strength peak was calculated according to Eq. (1), for specimens with rectangular cross sections.

$F=\frac{3 P L}{2 b d^{2}}$

where is the $F$ the flexural strength (MPa), $P$ is the maximum load at failure (N), $L$ is the support span $(50 \mathrm{~mm}), b$ is the average width of the sample $(10 \mathrm{~mm})$ and $d$ is the average height $(10 \mathrm{~mm})$. 
Table 2

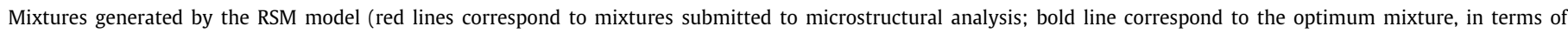
compressive strength).

\begin{tabular}{|c|c|c|c|c|c|c|c|}
\hline \multirow[t]{2}{*}{ Mixture ID } & \multirow[t]{2}{*}{ Activator index (X) } & \multirow[t]{2}{*}{ Precursor index $(\mathrm{Y})$} & \multirow[t]{2}{*}{ SH concentration (Z) } & \multicolumn{2}{|c|}{ Precursor (\%) } & \multicolumn{2}{|c|}{ Activator (\%) } \\
\hline & & & & SG & $\mathrm{FA}$ & SS & $\mathrm{SH}$ \\
\hline 1 & 1.0 & 1.0 & 0.0 & 100 & 0 & 100 & 0 \\
\hline 2 & 1.0 & 0.50 & 0.0 & 50 & 50 & 100 & 0 \\
\hline 3 & 0.50 & 0.50 & 8.0 & 50 & 50 & 50 & 50 \\
\hline 4 & 0.75 & 0.75 & 12.0 & 75 & 25 & 75 & 25 \\
\hline 5 & 0.75 & 0.75 & 10.0 & 75 & 25 & 75 & 25 \\
\hline 6 & 1.0 & 1.0 & 0.0 & 100 & 0 & 100 & 0 \\
\hline 7 & 0.75 & 0.75 & 10.0 & 75 & 25 & 75 & 25 \\
\hline 8 & 0.50 & 0.50 & 12.0 & 50 & 50 & 50 & 50 \\
\hline 9 & 1.0 & 0.50 & 0.0 & 50 & 50 & 100 & 0 \\
\hline 10 & 0.75 & 0.50 & 10.0 & 50 & 50 & 75 & 25 \\
\hline 11 & 0.75 & 0.75 & 8.0 & 75 & 25 & 75 & 25 \\
\hline 12 & 0.75 & 1.0 & 10.0 & 100 & 0 & 75 & 25 \\
\hline 13 & 0.50 & 1.0 & 8.0 & 100 & 0 & 50 & 50 \\
\hline 14 & 1.0 & 0.75 & 0.0 & 75 & 25 & 100 & 0 \\
\hline 15 & 0.50 & 0.75 & 10.0 & 75 & 25 & 50 & 50 \\
\hline 16 & 0.50 & 1.0 & 12.0 & 100 & 0 & 50 & 50 \\
\hline
\end{tabular}

After levelling the surfaces of the two remaining halves, these were tested for unconfined compression strength, following EN 196-1 [38], with a loading speed of $0.07 \mathrm{kN} / \mathrm{s}$, taking the average of the compression strength of the two halves as the final value of the unconfined compression strength.

Specimens from the tested flexural and compression strength specimens were collected for X-ray diffraction (XRD), Scanning Electron Microscope (SEM) and Energy Dispersive Spectroscopy (EDX) in four selected mixtures (mixtures 5, 10, 11 and 15). Mixture 5 , being a central point, is one of special importance, as it can be compared with all the others that change just one variable. For instance, mixtures 5 and 10 have the same SH molal concentration but different ratios of slag and fly ash. The only difference between mixture 5 and 11 is the sodium hydroxide molal concentration, and between 5 and 15 the only difference is the ratio between sodium silicate and sodium hydroxide. For this reason, these mixtures were chosen for microstructural analysis.

\section{Results and discussion}

\subsection{Flexural and compressive strength}

The results of flexural and compression strength tests are presented in Figs. 3 and 4, respectively, taking the average value of the three tested specimens of the same mixture at the same age. All the tested mixtures showed compression strength values above $10 \mathrm{MPa}$, after 7 days curing, which is deemed satisfactory for the envisaged application. The authors tested very similar mixtures in previous research $[4,33]$, with the same raw materials and compositions, obtaining significantly lower strength values, which was a consequence of the fact that both the fly ash and the slag were not milled, indicating that this has a determinant influence on the precursor reactivity. The central point results (mixtures 5 and 7 ) were quite similar between them, giving a positive feedback about the methodology and increasing the confidence on the reproducibility of the results. Additionally, it is also clear from the presented results that the mixtures with slag and fly ash have higher strength than the mixture with only slag (mixtures 1, 6, 12, 13 , and 16), indicating that the presence of fly ash is important to increase the silica content needed to the N-A-S-H gel structure. It should be also pointed out that these strength values are lower than what is generally obtained with blast furnace slags [39-41], although enough for most geotechnical applications.

\subsection{Response surface method (RSM)}

The advantage of the RSM is that it can analyse all the experimental results together instead of looking at each result individu-

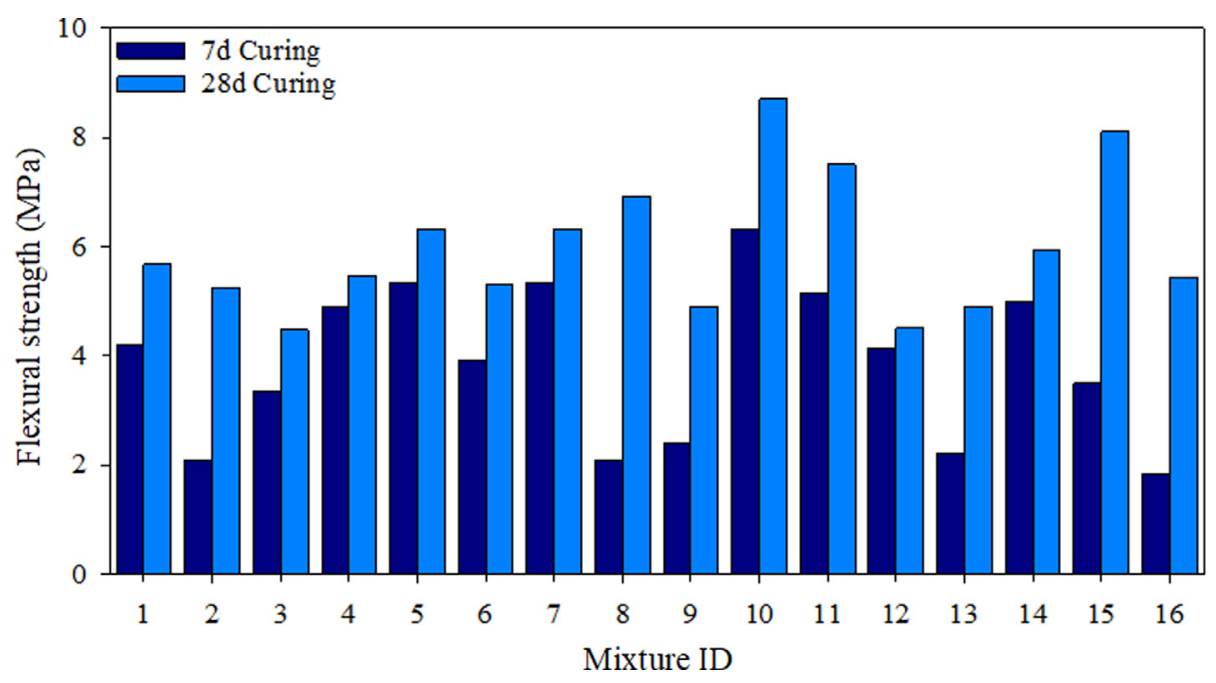

Fig. 3. Flexural strength of all mixtures tested, after 7 and 28 days curing. 


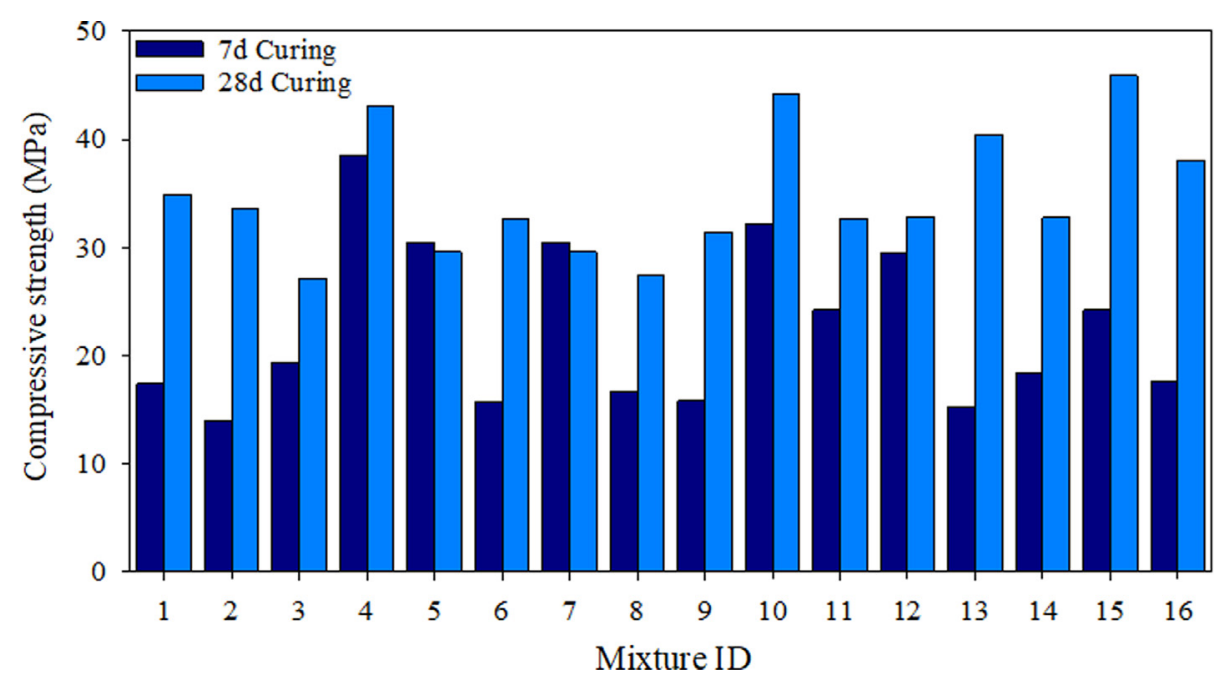

Fig. 4. Compressive strength of all mixtures tested, after 7 and 28 days curing.

ally or in average as presented above. For the statistical analysis of the results, all the 96 results were introduced in two RSM commercial software's (JMP7 ${ }^{\circledR}$ and Minitab1 $8^{\circledR}$ ) which allow slightly different outputs. This analysis provides three regression equations for each output variable (flexural and compressive strength), at each curing period, which describe and estimate the mechanical behaviour of the material. These equations describe the relationship between the output and input variables, namely the mechanical response and the mixture constitution, with an algebraic representation of the response surface. Eqs. (2) and (3) address the flexural strength, while Eqs. (4) and (5) address the compression strength for the two curing periods. From these equations it is also perceived that the variable $\mathrm{X}$ (the activator index) is the most important variable, followed by variable $Y$ (the precursor index) and the sodium hydroxide concentration (variable $\mathrm{Z}$ ). The smaller influence of this latter, in agreement with Fig. 7, can be explained by the small range of variation used in this study. In fact, the purpose of the sodium hydroxide is to keep the $\mathrm{pH}$ within a certain value to enable the effectiveness of the grout in all mixtures at low curing temperature. Other studies analysing a broader range of variation have found that very high sodium hydroxide concentrations can delay the polymerisation reaction as explained by Alonso \& Palomo [42].

$$
\begin{aligned}
F S_{7 \text { days }}= & 5.17-106 X+25.5 Y+2.74 Z+88.30 X^{2}-11.15 Y^{2} \\
& -0.14 Z^{2}-2.6 X Y+0.59 X Z-0.73 Y Z \\
F S_{28 \text { days }}= & -52.91+30 X+44.3 Y+5.75 Z+10 X^{2}-19.77 Y^{2} \\
& -0.15 Z^{2}-13.8 X Y-3.52 X Z-0.88 Y Z
\end{aligned}
$$
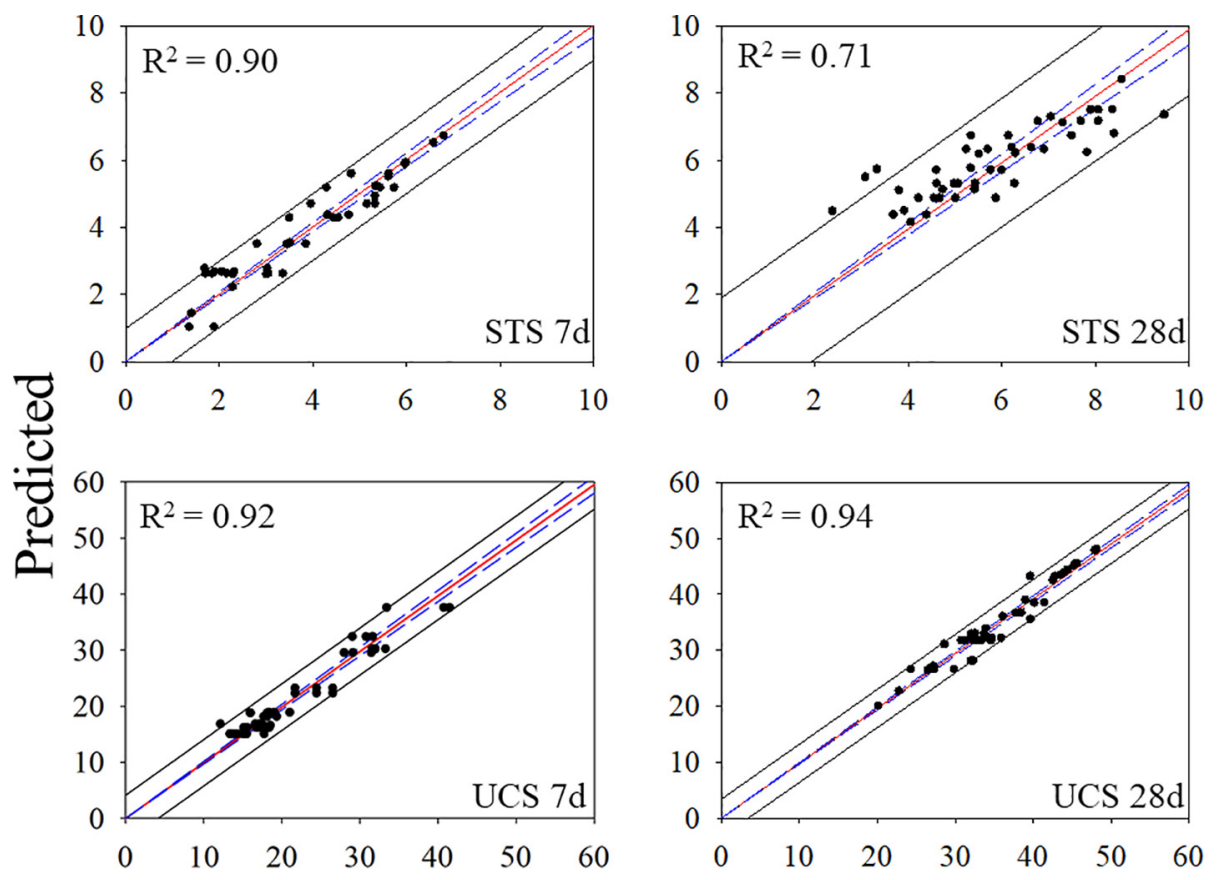

Actual

Fig. 5. Relationships between predicted (Predicted) and experimental (Actual) values for the output variables. The flexural strength is indicated as STS - splitting tensile strength while the compressive strength is indicated by UCS - unconfined compression strength. 


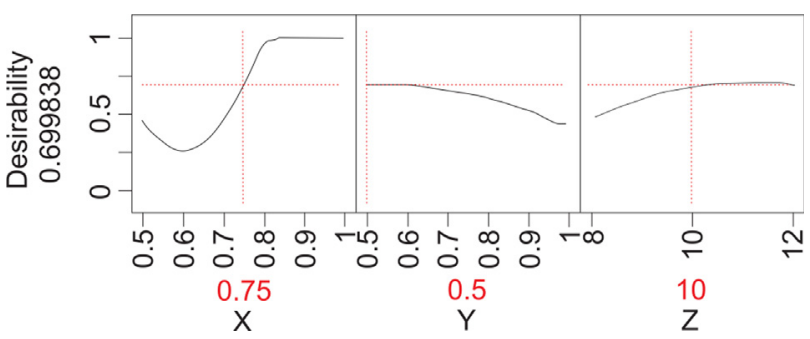

Fig. 6. Prediction profile for the ideal mixture showed in this study $\left(J M P 7^{\circledR}\right)$.

$$
\begin{aligned}
C S_{7 \text { days }}= & 304.7-1099 X+51.3 Y+2.83 Z+788 X^{2}-40.5 Y^{2} \\
& -0.51 Z^{2}-11.7 X Y+14.56 X Z-0.07 Y Z \\
C S_{28 \text { days }}= & 251-1111 X+179.2 Y+9.5 Z+883 X^{2}-16.7 Y^{2} \\
& -0.57 Z^{2}-153.3 X Y+11.37 X Z-5.52 Y Z
\end{aligned}
$$

In this type of statistical analysis, it is important to evaluate if the model was well adjusted and if the tests developed agree with the initial design. The model allows such type of data analysis by organising the information as shown in Fig. 5, where the output variable obtained in each test (Actual), is shown as a function of the value predicted by the model (Predicted). In short, the closer the points are disposing in a diagonal line, the better is the model.

The red line in the charts represents the linear regression, with the corresponding $\mathrm{R}^{2}$ coefficient, while the blue dotted lines represents the confidence interval $(\mathrm{CI})$, with a $95 \%$ confidence. The two black lines represent the prediction interval (PI) which is an estimation of the range where new data, obtained in the same context, will be contained, with a given probability. The main difference between the PI and the $\mathrm{CI}$ is that, while the $\mathrm{CI}$ is determined only with the data obtained from the specimen, the PI is established using a linear regression model. It is also clear from Fig. 5 that the flexural strength has higher dispersion that compressive strength, which in agreement with several other published results.

The model optimization presents the highest value that, theoretically, can be obtained, based on the data feed, as well as the conditions that will allow this value to be reached. In this study, such information is given in Fig. 6, as a function of the input variables X, Y and Z. The 'Desirability' value evaluates how well the variables can be combined to reach the optimal response (i.e. the highest strength). 'Individual Desirability' evaluates how each setting optimizes a single response (for instance, for a single curing time and type of strength) while 'Composite Desirability' evaluates how the definitions optimize a global set of responses (in this case for flexural and compressive strength at the two curing periods). The 'Composite Desirability' ranges between 0 and 1 , with ' 1 ' representing the 'ideal' case and ' 0 ' indicating that one or more responses are outside their acceptable limits.

The optimal mixture indicated by the prediction profile showed in Fig. 6 has values of $X=0.75, Y=0.5$ and $Z=10$, which is the same composition used for mixture 10. Although this mixture did not show the best mechanical results after $28 \mathrm{~d}$ curing, it is, nevertheless, very similar to mixture 15 , which indeed presented the highest compressive strength after $28 \mathrm{~d}$. The RSM considered this mixture as ideal based on the flexural strength data when it showed the highest results. Based in the experimental results (highest flexural strength and second-highest compressive strength), it can be concluded that, globally, mixture 10 was indeed the most effective.

The 3D response surfaces associated with the statistical analysis are presented in Fig. 7, which can help in the interpretation of the results. A change in the response with the variations in $\mathrm{X}$ and $\mathrm{Y}$ can be observed, showing that these variables have a significant influ-
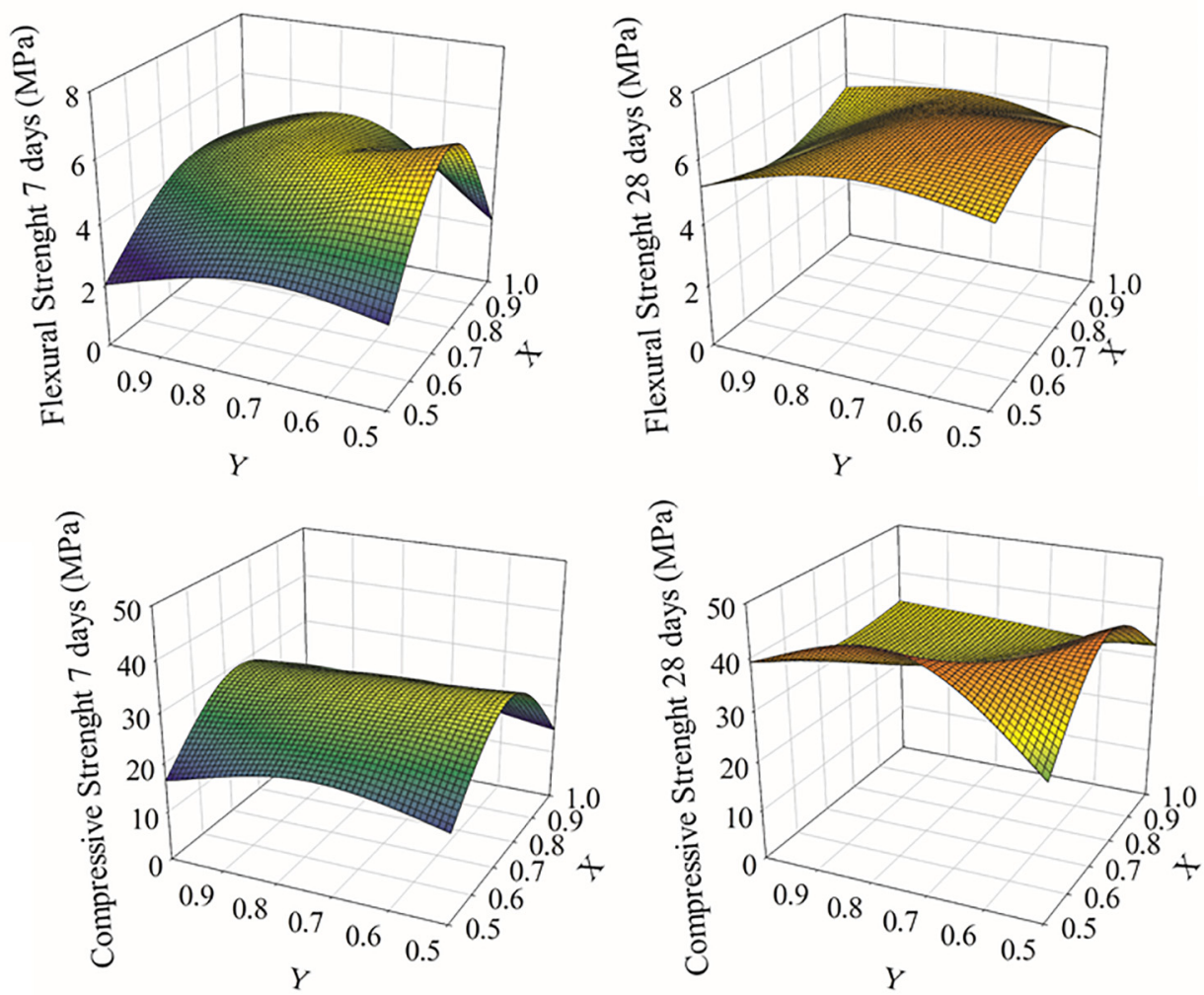

Fig. 7. Response surfaces for flexural and compression strength. 


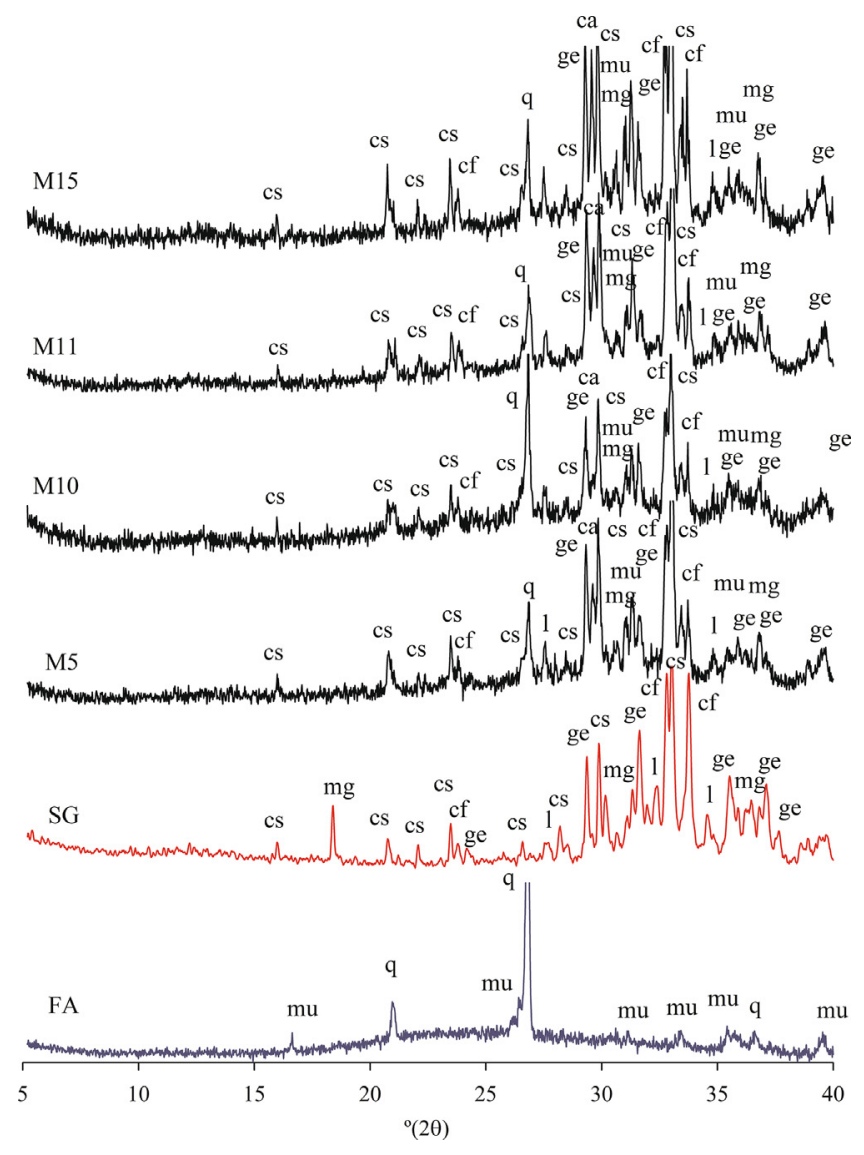

Fig. 8. X-ray diffractograms of the SG, FA, M5, M10, M11, M15 (legend: cf Calcium/Magnesium/Iron, cs - Calcium Silicate, ge - Gehlenite, 1 - Larnite, mg Magnetite, mu - Mullite, q - Quartz and ca - Calcite).

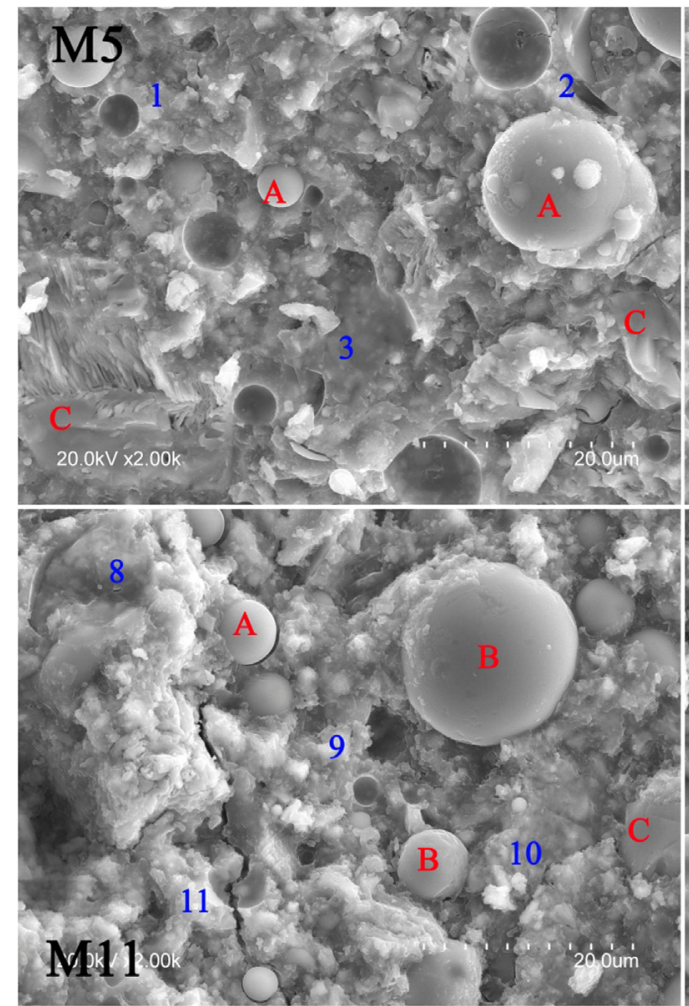

ence on the results, with the possible exception of the Y variable on the compressive strength after 7 days. From Fig. 7 it is also possible to observe the effectiveness of mixture 10 (Table 2).

\subsection{XRD analysis}

Fig. 8 presents the X-ray diffractograms of mixtures 5, 10, 11, and 15 , together with the original slag and fly ash, after curing for 28 days. As expected, given the fact that the M10 mixture is the only with a 50\% FA content (the remaining three have just $25 \%$ FA), this mixture's diffractogram showed the highest level of resemblance to the FA's diffractogram (e.g. the main quartz peak in the FA is more intense in the M10 than the remaining mixtures). The hump associated with the FA's amorphous content presented a shift to the right in the M10 and decreased in volume, a consequence of the formation of crystalline phases. However, even in this mixture the traces from the slag are more visible than those from the fly ash, indicating that, possibly, the latter contributed more to the development of the reaction products. The only new phase formed after the reactions was calcite, which has been associated with a strength increase when significant volumes are developed [43-45]. On the other hand, in Portland cement mixtures, calcite can enhance the strength gain by contributing to a more compacted morphology, closing the pores of the material. Although excessive calcite content can significantly decrease the $\mathrm{pH}$ (as calcium carbonate consumes alkalis in its formation), it is important to remember that a high alkalinity level is only essential during the initial stage of the reactions, when calcite was not yet fully established.

\subsection{SEM/EDX analysis}

The SEM images of M5, M10, M11, and M15 are presented in Fig. 9, together with the identification, using EDX, of some intact and partially attacked FA and SG particles. The general morphol-

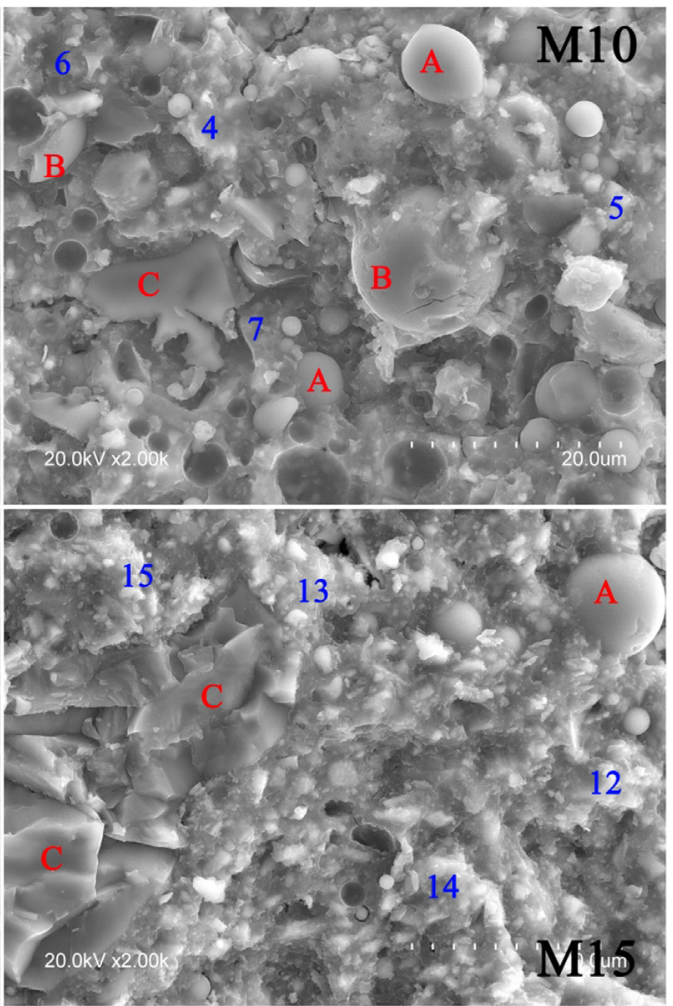

Fig. 9. Semi-quantitative SEM analysis of M5, M10, M11, and M15 mixtures, after 28 days curing ( $A=$ unreacted FA particle; B = partially reacted FA particle; $C=$ unreacted SG particle). 
Table 3

Characterisation of the gel points presented in Fig. 9.

\begin{tabular}{|c|c|c|c|c|c|c|c|c|}
\hline \multirow[t]{2}{*}{ Paste } & \multirow[t]{2}{*}{ Point } & \multicolumn{4}{|c|}{ Element content (wt\%) } & \multicolumn{3}{|c|}{ Molar ratios } \\
\hline & & $\mathrm{Si}$ & $\mathrm{Al}$ & $\mathrm{Na}$ & $\mathrm{Ca}$ & $\mathrm{Al}_{2} \mathrm{O}_{3} / \mathrm{SiO}_{2}$ & $\mathrm{CaO} / \mathrm{SiO}_{2}$ & $\mathrm{Na}_{2} \mathrm{O} / \mathrm{SiO}_{2}$ \\
\hline \multirow[t]{3}{*}{ M5 } & 1 & 17.4 & 6.0 & 4.5 & 26.7 & 0.305 & 1.0 & 0.165 \\
\hline & 2 & 14.7 & 4.5 & 5.8 & 24.0 & 0.272 & 1.1 & 0.250 \\
\hline & 3 & 11.2 & 3.2 & 3.0 & 18.6 & 0.252 & 1.1 & 0.168 \\
\hline \multirow[t]{4}{*}{ M10 } & 4 & 20.8 & 6.8 & 7.7 & 17.6 & 0.169 & 0.6 & 0.227 \\
\hline & 5 & 28.2 & 7.3 & 6.0 & 9.3 & 0.135 & 0.3 & 0.130 \\
\hline & 6 & 17.4 & 5.8 & 10.6 & 18.2 & 0.172 & 0.7 & 0.371 \\
\hline & 7 & 21.3 & 3.6 & 5.1 & 26.2 & 0.088 & 0.9 & 0.145 \\
\hline \multirow[t]{4}{*}{ M11 } & 8 & 17.6 & 6.0 & 5.2 & 25.6 & 0.179 & 1.0 & 0.180 \\
\hline & 9 & 16.5 & 8.3 & 4.2 & 26.7 & 0.263 & 1.1 & 0.153 \\
\hline & 10 & 19.6 & 4.1 & 4.5 & 27.4 & 0.110 & 1.0 & 0.138 \\
\hline & 11 & 16.4 & 3.8 & 7.6 & 29.9 & 0.122 & 1.3 & 0.284 \\
\hline \multirow[t]{4}{*}{ M15 } & 12 & 15.7 & 3.9 & 5.9 & 33.2 & 0.128 & 1.5 & 0.230 \\
\hline & 13 & 14.1 & 4.8 & 5.3 & 31.4 & 0.303 & 1.5 & 0.238 \\
\hline & 14 & 13.4 & 3.2 & 5.7 & 32.2 & 0.123 & 1.7 & 0.261 \\
\hline & 15 & 14.9 & 2.8 & 6.6 & 16.9 & 0.159 & 1.1 & 0.228 \\
\hline
\end{tabular}

ogy, showing a clear heterogeneity in all mixtures, seems to indicate that the reaction degree was not optimum, as several particles can still be seen unaffected. However, a dense and apparently wellcemented structure was developed for each case, contrary to the strength levels registered, which varied significantly. This suggests that the magnitude of the flexural and compressive strength was a consequence of the quality of the gel developed by each precursor/ activator combination. Also identified in these micro photos are some of the extensive number of points collected from the gel phase developed within each paste, points which are fully characterised in Table 3.

Based on the contents of elements $\mathrm{Si}, \mathrm{Al}, \mathrm{Na}$ and $\mathrm{Ca}$, as well as on the $\mathrm{Al}_{2} \mathrm{O}_{3} / \mathrm{SiO}_{2}, \mathrm{CaO} / \mathrm{SiO}_{2}$ and $\mathrm{Na}_{2} \mathrm{O} / \mathrm{SiO}_{2}$ molar ratios, the main reaction product found in $\mathrm{M} 5$ can be classified as a C-A-S-H gel, while in M10, due to its higher FA and lower SG content, is closer to a N, C-A-S-H gel. Such difference, in terms of gel composition, helps to explain the fact that the more balanced M10 mixture showed the highest compressive strength for all curing periods, while the M5 mixture, closer to the typical C-S-H gel developed by Portland cement, showed high UCS for shorter curing periods (7 and 14 days), but not for the longest period of 28 days. The calcium-based cementitious systems tend to develop their respective stiffness at a faster rate than those based on aluminosilicate structures, like the ones obtained from class F fly ash [46-47]. Regarding the M11 and M15 mixtures, fabricated with the same precursor combination (25FA $+75 \mathrm{SG})$, but with a different activator, it is clear that the higher silicon content present in the M11 composition (silicate / hydroxide weight ratio of 0.75 , compared with the 0.50 used in the M15 composition) was transposed to the gel. However, this did not seem to have a positive effect in terms of strength enhancement, since the M15 mixture (with higher $\mathrm{CaO} / \mathrm{SiO}_{2}$ and $\mathrm{Na}_{2} \mathrm{O} / \mathrm{SiO}_{2}$ molar ratios) presented higher compressive strength values than the M11, for all curing periods. Both these gels can be classified as C-A-S-H [8].

The composition of all points collected for each of the four mixtures is presented in the ternary diagrams shown in Fig. 10, to corroborate the respective gel type development proposed above. Based on the compositional diagram proposed by García-Lodeiro et al. [8], the M11 and M15 gels are clearly in the 'C-A-S-H' cluster, with 'Medium' to 'High' calcium contents. Alternatively, due to its low $\mathrm{Al}$ content, these can also be regarded as ' $\mathrm{C}-(\mathrm{A})-\mathrm{S}-\mathrm{H}$ ' gel types. The gel produced by $\mathrm{M} 5$, although showing higher $\mathrm{Al}$ contents and, thus, several points outside the classic C-A-S-H area, is not yet considered a N,C-A-S-H gel. On the contrary, the M10 mixture, with the lowest SG (i.e. calcium) content, is spread between the C-A$\mathrm{S}-\mathrm{H}$ and N,C-A-S-H areas, but most of its spots are located in the latter, thus the classification as a calcium substituted N-A-S-H gel (i.e. N,C-A-S-H) [8-48]. These results indicate that the type of gel developed is mostly influenced by the calcium content in the precursor, which, in this case, means that the gel depends on the slag content.

Regarding the influence of the silica, alumina and calcium oxide contents on the mechanical strength, and based on a direct comparison between mixtures M11 and M15, and M5 and M10, it appears that both the type of activator (first group) and the precursor composition (second group) were relevant to the final mechanical strength. In the first case, a lower soluble silica content and a
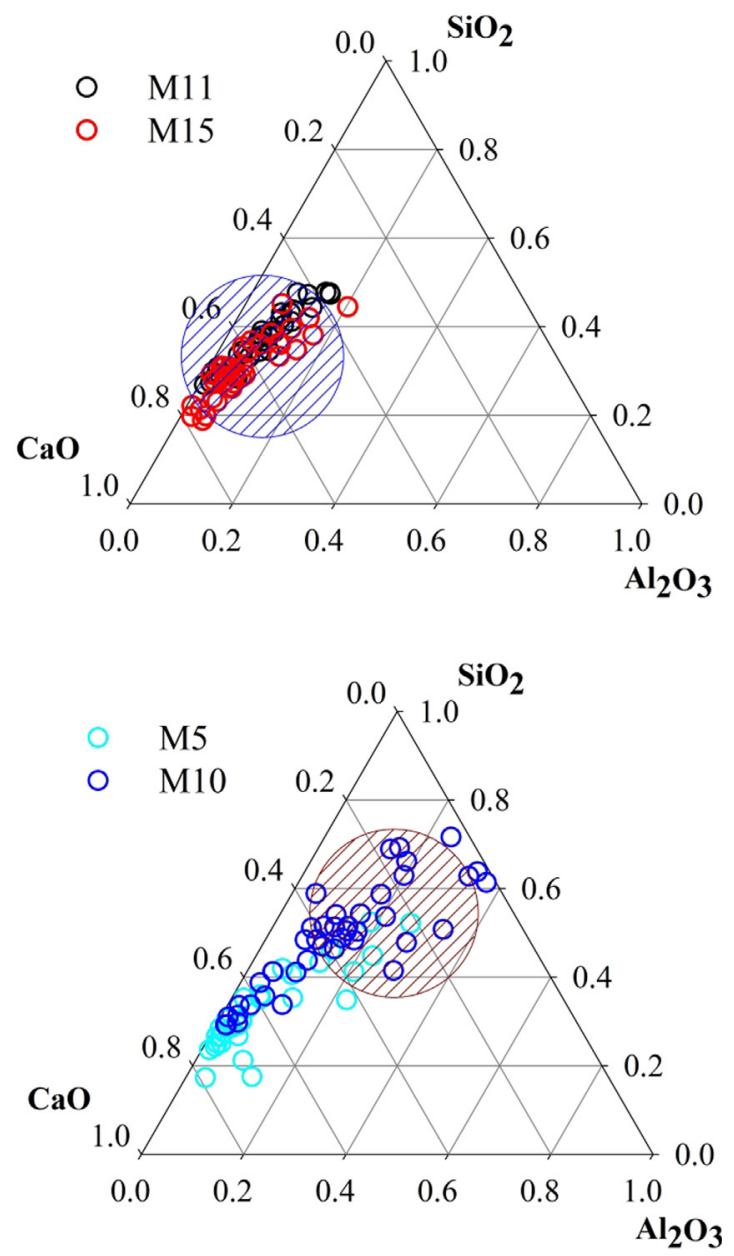

Fig. 10. Ternary diagrams (CaO-SiO2-Al2O3) based on EDX analysis of the gel composition of M5, M10, M11, and M15 mixtures, after 28 days curing. Points included in the blue circle translate a C-A-S-H gel, while points inside the red circle are closer to a N,C-A-S-H gel. 
higher alkali concentration (M15) produced a better-performing gel, with generally higher calcium oxide contents, for the same alumina content. Similar conclusions were previously reported by Abdollahnejad et al. [49], whom concluded that the Ca/Si molar had the highest impact on the mechanical strength of alkaliactivated ceramic/slag based binders, with an optimum range at 0.60 to 0.65 .

However, in the second case, a lower slag content (i.e. a lower calcium oxide content) generated a gel with a higher silica content (M10), which favoured the final mechanical behaviour, in detriment of a more balanced silica/calcium oxide composition (M5). Nevertheless, in this case the alumina content also changed significantly, with the higher strength gel showing higher silica and alumina contents than the higher Ca content. It can be assumed that the incorporation of calcium is generally positive, in terms of mechanical behaviour, but only up to a certain degree, when it starts to deplete the structural matrix of the essential silicon and aluminium ions Abdollahnejad et al. [50].

In both cases, the slight variations on the activator or precursor were able to produce significant responses in terms of compressive strength, as the differences between M11 and M15, and between M5 and M10 were approximately 50\%.

\section{Conclusions}

This paper presents the mechanical and microstructural characterization of a cementing material resulting from the alkaline activation of slag and fly ash which creates a semi-crystalline gel that has similar properties to the C-S-H gel resulting from ordinary Portland cement. This type of binder is nowadays the focus of extensive research, mostly due to its sustainability compared to traditional cement. However, studies addressing the optimisation of the experimental process are scarce, even if the quantity of variables with influence on the quality of the final product, is clearly higher than those affecting OPC results.

The mechanical performance of this new material was evaluated by unconfined flexural and compressive strength tests, analysed with a statistical model (response surface method) that provided regression models capable of predicting the flexural and compressive strength at two different curing ages. This was further analysed and compared with a microstructural analysis, including $\mathrm{X}$-ray diffraction, and scanning electron microscopy.

The specimens were cured without high temperature levels, contrary to what is commonly used in other works. Usually, mixtures based only on fly ash achieve good strength levels when high curing temperatures are used, due to its low calcium content. This parameter significantly affects the structural transition from the amorphous to the crystalline polymer of the synthesized mineral polymers. The partial replacement of ash with slag, rich in calcium, promotes the production of C-A-S-H or C,N-A-S-H type gels, which guarantee higher initial strengths. In fact, the best performing mixture (M10) developed a N,C-A-S-H gel, a clear indication of the favourable combination of calcium rich slag and low calcium fly ash.

The application of the response surface method provided the regression equations for the compressive and flexural strength at each age based on the mixture composition. It also provided the definition of the best performing composition using a rational methodology. It should be noted that the proposed regressions are only valid within the defined range of each variable. Further work is needed to enlarge the range of variation of the regression model.

The optimum composition obtained demonstrated significant mechanical performance at early or at older ages (32.27 MPa and 44.25 MPa of unconfined compression strength at 7 and 28 days respectively), even without curing at high temperatures, which is very important for the ground improvement applications.

\section{CRediT authorship contribution statement}

Claver Pinheiro: Formal analysis, Investigation, Writing - original draft. Sara Rios: Methodology, Resources, Supervision. António Viana Fonseca: Funding acquisition, Project administration, Supervision. Ana Fernández-Jiménez: Validation. Nuno Cristelo: Conceptualization, Writing - review \& editing.

\section{Declaration of Competing Interest}

The authors declare that they have no known competing financial interests or personal relationships that could have appeared to influence the work reported in this paper.

\section{Acknowledgments}

The authors would like to acknowledge the MCTES/FCT (Portuguese Science and Technology Foundation of Portuguese Ministry of Science and Technology) for their financial support through the SFRH/BPD/85863/2012 scholarship, which is cofunded by the European Social Fund by POCH program, and the $\mathrm{CNPq}$ (the Brazilian council for scientific and technological development) for its financial support in 201465/2015-9 scholarship of the "Science without borders" program. This work was also financially supported by: Base Funding - UIDB/04708/2020 of the CONSTRUCT - Instituto de I\&D em Estruturas e Construções funded by national funds through the FCT/MCTES (PIDDAC).

\section{References}

[1] U. Rattanasak, P. Chindaprasirt, Influence of $\mathrm{NaOH}$ solution on the synthesis of fly ash geopolymer, Miner. Eng. 22 (12) (Oct. 2009) 1073-1078.

[2] T. Poinot, M.E. Laracy, C. Aponte, H.M. Jennings, J.A. Ochsendorf, E.A. Olivetti, Beneficial use of boiler ash in alkali-activated bricks, Resour. Conserv. Recycl. 128 (2018) 1-10.

[3] M.O. Baumbach, L.T.S. Ramos, R.P. Batista, R.D. Oliveira, P.H.R. Borges, Portland versus alkali-activated cement wall panels containing mine tailing as aggregate: one-story house thermal performance simulation in a Brazilian and Portuguese hot and humid climate, MATEC Web Conf. 274 (Feb. 2019) 03003.

[4] S. Rios, A. Viana da Fonseca, C. Pinheiro, S. Nunes, and N. Cristelo, Alkaliactivated cement using slags and fly ash, in WASTES - Solutions, Treatments and Opportunities II, CRC Press, 2017, pp. 161-166.

[5] S. Rios, N. Cristelo, A. Viana da Fonseca, C. Ferreira, A.V. da Fonseca, C. Ferreira, Stiffness behavior of soil stabilized with alkali-activated fly ash from small to large strains, Int. J. Geomech. 17 (3) (Mar. 2017) 04016087.

[6] A. Fernández-Jiménez, A. Palomo, M. Criado, Microstructure development of alkali-activated fly ash cement: A descriptive model, Cem. Concr. Res. 35 (6) (Jun. 2005) 1204-1209.

[7] A. Fernández-Jiménez, A. Palomo, I. Sobrados, J. Sanz, The role played by the reactive alumina content in the alkaline activation of fly ashes, Microporous Mesoporous Mater. 91 (1-3) (Apr. 2006) 111-119.

[8] I. Garcia-Lodeiro, A. Palomo, A. Fernández-Jiménez, D.E. Macphee, Compatibility studies between N-A-S-H and C-A-S-H gels. Study in the ternary diagram Na2O-CaO-Al2O3-SiO2-H2O, Cem. Concr. Res. 41 (9) (Sep. 2011) 923-931.

[9] S. Zhang, V.C. Li, G. Ye, Micromechanics-guided development of a slag/fly ashbased strain-hardening geopolymer composite, Cem. Concr. Compos. 109 (May 2020) 103510.

[10] A. Hajimohammadi, J.S.J. van Deventer, Characterisation of one-part geopolymer binders made from fly ash, Waste Biomass Valorization 8 (1) (Jan. 2017) 225-233.

[11] B. Nematollahi, J. Sanjayan, J. Qiu, E.-H. Yang, High ductile behavior of a polyethylene fiber-reinforced one-part geopolymer composite: A micromechanics-based investigation, Arch. Civ. Mech. Eng. 17 (3) (May 2017) 555-563.

[12] K. Wang, L. Du, X. Lv, Y. He, X. Cui, Preparation of drying powder inorganic polymer cement based on alkali-activated slag technology, Powder Technol. 312 (May 2017) 204-209.

[13] J.S.J. van Deventer, D. Feng, P. Duxson "Dry mix cement composition, methods and system involving same," US Patent 7691198 B2 2010.

[14] C. Shi, Characteristics and cementitious properties of ladle slag fines from steel production, Cem. Concr. Res. 32 (3) (Mar. 2002) 459-462. 
[15] M. Mastali, A. Alzaza, K.M. Shaad, P. Kinnunen, Z. Abdollahnejad, B. Woof, M. Illikainen, Using carbonated BOF slag aggregates in alkali-activated concretes, Materials (Basel) 12 (8) (Apr. 2019) 1288.

[16] P. J. Whitcomb and M. J. Anderson, RSM Simplified: Optimizing Processes Using Response Surface Methods for Desigh of Experiment. CRC press, 2004

[17] J.F. Rivera, N. Cristelo, A. Fernández-Jiménez, R. Mejía de Gutiérrez, Synthesis of alkaline cements based on fly ash and metallurgic slag: Optimisation of the $\mathrm{SiO} 2 / \mathrm{Al} 2 \mathrm{O} 3$ and $\mathrm{Na2O} / \mathrm{SiO} 2$ molar ratios using the response surface methodology, Constr. Build. Mater. 213 (Jul. 2019) 424-433.

[18] S. Nunes, P. Milheiro-Oliveira, J.S. Coutinho, J. Figueiras, Robust SCC Mixes through Mix Design, J. Mater. Civ. Eng. 25 (2) (Feb. 2013) 183-193.

[19] A.S. Brand, J.R. Roesler, Steel furnace slag aggregate expansion and hardened concrete properties, Cem. Concr. Compos. 60 (Jul. 2015) 1-9.

[20] Y. Wang, P. Suraneni, Experimental methods to determine the feasibility of steel slags as supplementary cementitious materials, Constr. Build. Mater. 204 (Apr. 2019) 458-467.

[21] E. Adesanya, H. Sreenivasan, A.M. Kantola, V.V. Telkki, K. Ohenoja, P. Kinnunen, M. Illikainena, Ladle slag cement - Characterization of hydration and conversion, Constr. Build. Mater. 193 (Dec. 2018) 128-134.

[22] S. Choi, J.M. Kim, D. Han, J.H. Kim, Hydration properties of ladle furnace slag powder rapidly cooled by air, Constr. Build. Mater. 113 (Jun. 2016) 682-690.

[23] C.A. Cárdenas Balaguera, M.A. Gómez Botero, Characterization of steel slag for the production of chemically bonded phosphate ceramics (CBPC), Constr. Build. Mater. 241 (Apr. 2020) 118138.

[24] E. Adesanya, K. Ohenoja, P. Kinnunen, M. Illikainen, Properties and durability of alkali-activated ladle slag, Mater. Struct. Constr. 50 (6) (Dec. 2017) 255

[25] H. Nguyen, E. Adesanya, K. Ohenoja, L. Kriskova, Y. Pontikes, P. Kinnunen, M. Illikainen, Byproduct-based ettringite binder - A synergy between ladle slag and gypsum, Constr. Build. Mater. 197 (Feb. 2019) 143-151.

[26] American Society for Testing and Materials, ASTM C618-19, Standard Specification for Coal Fly Ash and Raw or Calcined Natural Pozzolan for Use in Concrete, Annu. B. ASTM Stand., no. C, p. 5, 2019.

[27] A. Fernández-Jiménez, A. Palomo, Characterisation of fly ashes. Potential reactivity as alkaline cements, Fuel 82 (18) (Dec. 2003) 2259-2265.

[28] N. Cristelo, S. Glendinning, T. Miranda, D. Oliveira, R. Silva, Soil stabilisation using alkaline activation of fly ash for self compacting rammed earth construction, Constr. Build. Mater. 36 (11) (Nov. 2012) 727-735.

[29] D. Hardjito, S.E. Wallah, D.M.J. Sumajouw, B.V. Rangan, Factors influencing the compressive strength of fly ash-based geopolymer concrete, Civ. Eng. Dimens 6 (2) (2004) 88-93.

[30] K. Kupwade-Patil, E.N. Allouche, Impact of alkali silica reaction on fly ashbased geopolymer concrete, J. Mater. Civ. Eng. 25 (1) (Jan. 2013) 131-139.

[31] S. Rios, N. Cristelo, A. Viana da Fonseca, C. Ferreira, Structural performance of alkali-activated soil ash versus soil cement, J. Mater. Civ. Eng. 28 (2) (Feb. 2015) 04015125

[32] N. Cristelo, E. Soares, I. Rosa, T. Miranda, D.V. Oliveira, R.A. Silva, A. Chaves, Rheological properties of alkaline activated fly ash used in jet grouting applications, Constr. Build. Mater. 48 (Nov. 2013) 925-933.

[33] C. Pinheiro, F. A. Molina-Gómez, S. Rios, A. Viana da Fonseca, and F. Sousa, "Análise estatística proporcional dos constituintes de um ligante alternativo utilizado em reforço de solos," in $16^{\circ}$ Congreso nacional de geotecnia - 6as Jornadas Luso-Españolas de Geotecnia, 2018, p. \# 311.

[34] I. Phummiphan, S. Horpibulsuk, P. Sukmak, A. Chinkulkijniwat, A. Arulrajah, S.L. Shen, Stabilisation of marginal lateritic soil using high calcium fly ash-based geopolymer, Road Mater. Pavement Des. 17 (4) (Oct. 2016) 877-891.

[35] H. Xu, J.S.J. Van Deventer, The effect of alkali metals on the formation of geopolymeric gels from alkali-feldspars, Colloids Surfaces A Physicochem. Eng. Asp. 216 (1-3) (Apr. 2003) 27-44.

[36] M. Mastali, K.M. Shaad, Z. Abdollahnejad, M. Falah, P. Kinnunen, M. Illikainen, Towards sustainable bricks made with fiber-reinforced alkali-activated desulfurization slag mortars incorporating carbonated basic oxygen furnace aggregates, Constr. Build. Mater. 232 (Jan. 2020) 117258.

[37] A. Koch, H. Steinegger, A rapid method for testing the resistance of cements to sulphate attack, Zement-Kalk-Gips 13 (7) (1960) 317-324.

[38] EN196-1, Methods of testing cement - Part 1: Determination of strength, Eur. Stand., pp. 1-33, 2006.

[39] A. Rajarajeswari, G. Dhinakaran, Compressive strength of GGBFS based GPC under thermal curing, Constr. Build. Mater. 126 (Nov. 2016) 552-559.

[40] S. Shin, G. Goh, C. Lee, Predictions of compressive strength of GPC blended with GGBFS developed at varying temperatures, Constr. Build. Mater. 206 (May 2019) 1-9.

[41] S. Sim, D. Jeon, W.S. Yum, H. Song, D.H. Kim, J.E. Oh, Development of a clinkerfree white binder of one-part CaO-activated GGBFS with TiO2 addition, Constr. Build. Mater. 248 (Jul. 2020) 118705.

[42] S. Alonso, A. Palomo, Alkaline activation of metakaolin and calcium hydroxide mixtures: influence of temperature, activator concentration and solids ratio, Mater. Lett. 47 (1-2) (Jan. 2001) 55-62.

[43] M. Merabtene, L. Kacimi, P. Clastres, Elaboration of geopolymer binders from poor kaolin and dam sludge waste, Heliyon 5 (6) (Jun. 2019) e01938.

[44] C. K. Yip, G. C. Lukey, and J. S. J. van Deventer Dean, Effect of Blast Furnace Slag Addition on Microstructure and Properties of Metakaolinite Geopolymeric Materials, in Advances in Ceramic Matrix Composites IX, 2012, pp. 187-209.

[45] C.K. Yip, G.C. Lukey, J.S.J. van Deventer, The coexistence of geopolymeric ge and calcium silicate hydrate at the early stage of alkaline activation, Cem. Concr. Res. 35 (9) (Sep. 2005) 1688-1697.

[46] N. Cristelo, A. Fernández-Jiménez, C. Vieira, T. Miranda, Á. Palomo, Stabilisation of construction and demolition waste with a high fines content using alkali activated fly ash, Constr. Build. Mater. 170 (May 2018) 26-39.

[47] N. Cristelo, S. Glendinning, A. Teixeira Pinto, Deep soft soil improvement by alkaline activation, Proceedings of the Institution of Civil Engineers - Ground Improvement 164 (2) (2011) 73-82.

[48] I. Ismail, S.A. Bernal, J.L. Provis, R. San Nicolas, S. Hamdan, J.S.J. van Deventer Modification of phase evolution in alkali-activated blast furnace slag by the incorporation of fly ash, Cem. Concr. Compos. 45 (2014) 125-135.

[49] Z. Abdollahnejad, T. Luukkonen, M. Mastali, P. Kinnunen, M. Illikainen, Development of one-part alkali-activated ceramic/slag binders containing recycled ceramic aggregates, J. Mater. Civ. Eng. 31 (2) (Feb. 2019) 04018386.

[50] Z. Abdollahnejad, A. Dalvand, M. Mastali, T. Luukkonen, M. Illikainen, Effects of waste ground glass and lime on the crystallinity and strength of geopolymers, Mag. Concr. Res. 71 (23) (Dec. 2019) 1218-1231. 